\title{
Indicators for suicide substrate inactivation: A kinetic investigation
}

\author{
SHARMISTHA DHATT* \\ Department of Chemistry, University of Calcutta, 92, A. P. C. Road, Kolkata, West Bengal 700 009, India \\ E-mail: pcsdhatt@gmail.com
}

MS received 20 August 2017; revised 12 October 2017; accepted 28 October 2017; published online 20 November 2017

\begin{abstract}
Suicide substrate kinetic pathway and a proposed set of indicators, some theoretical and a few practical ones, that can decisively conclude enzyme inactivation are considered. Steady-state approximation is assumed not only when a catalytic amount of enzyme is used but also for any substrate-enzyme ratio. In each situation, adequacy of the approximation is numerically tested. An equation for the rate of inactivation of the enzyme has been derived and employed under suitable approximations to estimate various indicators. Progressive curves for such indicators via numerical simulation are shown that decide impromptu inactivation too. The scheme though is a traditional one, the findings are novel.
\end{abstract}

Keywords. Suicide inhibitor; mechanism-based inhibitor; drug specificity; fractional-life; enzyme inactivation.

\section{Introduction}

Mechanism-based inactivation ${ }^{1,2}$ of target enzymes is a fascinating area of interdisciplinary research at the interphase of chemistry, biology and medicine. With the resurgence of interest among academic and industrial researchers alike, 'suicidal-inactivation, ${ }^{3-14}$ has become a leading approach in studying enzyme mechanism and rational designing of the novel and effective drugs in the pharmaceutical industry.

Physiologically, suicide-substrate systems target specific enzymes for inactivation, thereby reducing their activity, thus preventing substrate utilization and product formation. The outcome of this chemical intervention in biological systems is sometimes beneficial like, blocking of pathogenic enzymes, production of toxic constituents, etc. Most popular clinical examples of suicide-substrate include Aspirin (inhibits cyclooxygenase 1 and 2 enzymes), Exemesteme - a drug used in the treatment of breast cancer (inhibitor of aromatase enzyme), AZT and other nucleoside analogues used in the treatment of AIDS/HIV (inhibits HIV-1 reverse transcriptase), Penicillin, etc., and the list is exhaustive. Apoptosis, a distinct form of programmed cell death that plays a major role in diseases like cancer, HIV, neurogenetive disorder occurs through cell suicide programme as well.

Despite the importance of the mechanism, ${ }^{11-14}$ there have been very few detailed studies of the kinetics that have developed to the point of usefulness. The phenomenon was discussed thoroughly by Walsh, ${ }^{8}$ Waley, ${ }^{4,5}$ Burke, ${ }^{1}$ Tatsunami $^{3}$ and Goeke; ${ }^{2}$ but, the emphasis was always on high substrate-enzyme ratio and partition ratio. Kinetic parameters for such a system were determined along with some other conditions for an effective suicide-substrate that has been modified from time to time. More specifically, those prevalent indicators have a much limited scope of application since they demand substrate-excess systems only. This is the gap that our article seeks to fill.

The present article intends to find, (i) suitable indicators, both theoretical and experimental, when the substrate is not in excess in a system just as in cellular environment; (ii) situations where even when the substrate is in excess the prevalent indicators do not always lead to a correct conclusion. This article attempts to test the indicators in such situations too. Numerical simulation studies on some proposed indicators are presented to inquire specifically whether the target enzyme is committing suicide everywhere.

\footnotetext{
*For correspondence

Electronic supplementary material: The online version of this article (https://doi.org/10.1007/s12039-017-1400-5) contains supplementary material, which is available to authorized users.
} 


\section{Theoretical}

The coupled differential equations for the kinetic scheme are difficult to solve analytically. The system of Ordinary Differential Equations is solved numerically. To retain the accuracy of such a non-linear set of equations, one needs to be extremely cautious. Thus, in all cases of simulation, $4^{\text {th }}$ order Runge-Kutta method with a time step of order $10^{-3}-10^{-4}$ was used both in FORTRAN and MAPLE environments.

The scheme and working equations are

$$
\begin{gathered}
E+S \underset{k_{2}}{\stackrel{k_{1}}{\leftrightarrows}} C_{1} \stackrel{k_{3}}{\longrightarrow} C_{2} \stackrel{k_{4}}{\longrightarrow} E+P \\
C_{2} \stackrel{k_{5}}{\longrightarrow} E_{i}
\end{gathered}
$$

The suicide-substrate mechanism to be investigated in the present note involves a substrate $S$, an enzyme $E$, two intermediate complexes $C_{1}$ and $C_{2}$, an inactivated complex $E_{i}$ and product $P$. Here $S$ is the suicide substrate, a substrate analogue that binds with the enzyme, but enzyme interaction converts it to an inhibitor that irreversibly inactivates the enzyme. 'Irreversible inactivation of the enzyme' implies that the enzyme has in some way or form been permanently modified since it can no longer carry out its function. The enzyme thus commits suicide, hence the name. These are also called 'Trojan horse inhibitors'. These reactive functionalities can then irreversibly alkylate a nucleophilic amino acid residue or cofactor present in the enzyme and in essence, causes the enzyme's death ('suicide'). These inhibitors have a latent reactive functionality that only becomes apparent after binding and have one more level of selectivity built into them. For this class of inhibitors to be classified as suicide substrate, some criteria include; (i) inactivation should be time-dependent, (ii) reaction should be first-order, (iii) the enzyme should show saturation phenomenon, (iv) substrate should be able to protect the enzyme and stoichiometry of the reaction should be 1:1 (i.e., one active site to one inhibitor). Mass action kinetics and stoichiometry lead to the following coupled differential equations

$$
\begin{aligned}
& \frac{d s}{d t}=-k_{1} e . s+k_{2} c_{1} \\
& \frac{d e}{d t}=-k_{1} e . s+k_{2} c_{1}+k_{4} c_{2} \\
& \frac{d c_{1}}{d t}=k_{1} e . s-\left(k_{2}+k_{3}\right) c_{1} \\
& \frac{d c_{2}}{d t}=k_{3} c_{1}-\left(k_{4}+k_{5}\right) c_{2} \\
& \frac{d e_{i}}{d t}=k_{5} c_{2} \\
& \frac{d p}{d t}=k_{4} c_{2}
\end{aligned}
$$

The relevant initial conditions are $s(t=0)=s_{0}, c_{1}(t=$ $0)=c_{2}(t=0)=e_{i}(t=0)=0$. Like most of the articles, ${ }^{3,4}$ a quasi steady state approximation (QSSA) for both the complexes is assumed. The system of equations is further simplified using mass conservation equations:

$$
\begin{aligned}
& e_{0}=e+c_{1}+c_{2}+e_{i} \\
& s_{0}=s+c_{1}+c_{2}+e_{i}+p
\end{aligned}
$$

The reduced system will contain only four coupled differential equations, but still these are too difficult to solve analytically without certain relevant approximations. So, numerical simulations are carried out to illustrate certain points. The biologically relevant questions that arise are, (i) whether the substrate will be converted via the catalytic route, and (ii) whether all the enzymes will be inactivated. These points will be looked into in detail.

\subsection{Prevalent conditions for suicide substrate}

Waley ${ }^{4}$ proposed the condition that determines whether most of the enzyme will be inactivated without substrate being exhausted

$s_{0} / e_{0}>r$

where $r=\frac{k_{4}}{k_{5}}$ is the partition ratio that governs the ratio of the products formed in any parallel pathway kinetics. The condition ( $2 a$ ) is reversed if the situation is otherwise implying the suicidal inactivation is absent under enzyme excess case. Tatsunami et al., ${ }^{3}$ on the other hand, found the formative factor for enzyme inactivation in suicide-substrate system as,

$$
\begin{aligned}
& s_{0} / e_{0}>(1+r) \\
& s_{0} / e_{0}<(1+r) \\
& s_{0} / e_{0}=r
\end{aligned}
$$

where $r$ is again the partition ratio. The article calls these expressions as indicator $\mathrm{I}_{1}$. Goeke et al., in their limit set analysis $^{2}$ supported the conclusions of Tatsunami et al., ${ }^{3}$ without assuming QSSA. Here also the emphasis was on substrate excess systems, as the previously steady state is assumed under such conditions only. We shall scrutinize the workability of such endeavours and will extend the scope of suicidal inactivation under conditions of comparable and excess enzyme cases as well.

\subsection{Kinetic Analysis}

Assuming QSSA for the intermediate complexes yield

$\bar{c}_{1}=\frac{k_{1} \bar{e} \cdot \bar{s}}{\left(k_{2}+k_{3}\right)} \quad \bar{c}_{2}=\frac{k_{1} k_{3} \bar{e} \cdot \bar{s}}{\left(k_{2}+k_{3}\right)\left(k_{4}+k_{5}\right)}$

So, the complexes bear a relation between themselves

$\bar{c}_{2}=K^{\prime} \bar{c}_{1}$

where $K^{\prime}=k_{3} /\left(k_{4}+k_{5}\right)$.

It is pertinent to mention that like Michaelis-Menten type system, the focus is on the initial phase kinetics of the suicidesubstrate system where product formation is too low and safely neglected to avoid very complicated equations for the purpose of analysis. The system was numerically simulated and constancy of the partition ratio and the conservation equations were checked to test the goodness of the effort using Runge-Kutta $4^{\text {th }}$ order programme. 


\subsection{A few more efficient indicators}

We intend to discuss a few more efficient indicators, some theoretical and a few experimental ones that may serve to identify suicidal inactivation.

\subsection{Fractional life of enzymes}

Temporal progressive curves for enzyme and inactivated enzyme offer a qualitative reflection of suicidal inactivation kinetics. For a quantitative theoretical estimation of the effectiveness of suicide substrate, the fractional life of enzyme may serve as an indicator to enzymologists and especially for the pharmacologists during drug administration and delivery, similar to antibiotic kinetics.

From (1b) we get,

$\frac{d e}{d t}=-k_{1} e . s+\bar{C} e . s=\left(\bar{C}-k_{1}\right) e . s$

where $\bar{C}=\left(k_{2}+k_{4} K^{\prime}\right) k_{1} /\left(k_{2}+k_{3}\right)$. Using (1g), (4a) is reduced to,

$\frac{d e}{d t}=-k_{1} e . s+\bar{C} e . s=\left(\bar{C}-k_{1}\right) e .(A+e)$

where $A=s_{0}-e_{0}$. Thus integrating with initial condition of $e(0)=e_{0}$,

$t=\frac{1}{A\left(\bar{C}-k_{1}\right)} \ln \left(\frac{e\left(A+e_{0}\right)}{e_{0}(A+e)}\right)$

For $\beta$ fraction of the enzyme remaining, i.e., $e=\beta e_{0}$,

$\tau_{\beta}=\frac{1}{A\left(\bar{C}-k_{1}\right)} \ln \left(\frac{\beta s_{0}}{s_{0}-e_{0}(1-\beta)}\right)$

Equation (4d) can be generalized for high substrate-enzyme ratio; i.e., $\left(s_{0} / e_{0}=\alpha\right)$ where $\alpha$ can assume value fractional (greater than 1) or integer, with $\tau_{\beta}$ modified to,

$\tau_{\beta}=\frac{1}{e_{0}(\alpha-1)\left(\bar{C}-k_{1}\right)} \ln \left(\frac{\alpha \beta}{\alpha+\beta-1}\right)$

However, the equation (4e) has an apparent shortcoming when the concentration of $e_{0}$ and $s_{0}$ are of the same order of magnitude i.e., $(\alpha=1)$. But a thorough analysis clarifies the point and we have analytical solutions uniformly valid for same enzyme-substrate ratio $\left(s_{0} / e_{0}=\alpha=1\right)$, thus,

$\frac{d e}{d t}=-k_{1} e . s+\bar{C} e . s=\left(\bar{C}-k_{1}\right) e^{2}$

which on integration with an initial condition of $e(0)=e_{0}$ gives,

$e=\frac{e_{0}}{1-e_{0}\left(\bar{C}-k_{1}\right) t}$

again with $\beta$ a fraction of the enzyme remaining i.e., $e=\beta e_{0}$,

$\tau_{\beta}=\frac{(1-\beta)}{e_{0} \beta\left(\bar{C}-k_{1}\right)}$

The equation $(4 \mathrm{c})$ will be modified for situations with excess enzyme cases where the value of $\mathrm{A}$ is negative and the differential equation is accordingly amended and integrated with the initial condition as above.

$t=\frac{1}{A\left(\bar{C}-k_{1}\right)} \ln \left(\frac{e_{0}(e-A)}{s_{0} e}\right)$

For $\beta$ fraction of the enzyme remaining i.e., $e=\beta e_{0}$,

$\tau_{\beta}=\frac{1}{A\left(\bar{C}-k_{1}\right)} \ln \left(\frac{(\beta+1) e_{0}-s_{0}}{s_{0} \beta}\right)$

Equation (4j) is applicable for low substrate-enzyme ratio i.e., $\left(s_{0} / e_{0}=\alpha\right)$ where $\alpha$ can assume value fractional (less than $1)$ or integer, with $\tau_{\beta}$ modified to,

$\tau_{\beta}=\frac{1}{e_{0}(\alpha-1)\left(\bar{C}-k_{1}\right)} \ln \left(\frac{(\beta+1)-\alpha}{\alpha \beta}\right)$

Thus equations $(4 \mathrm{e}),(4 \mathrm{~h})$ and $(4 \mathrm{k})$ serve as indicator $\mathrm{I}_{2}$ for different substrate-enzyme ratio as illustrated.

\subsection{Relative excess of inactivated enzyme}

Fidelity of some indicators over the other motivates one to look for some better indicators as well. This will be thoroughly discussed with relevant test cases in the next section.

(i) Inactivation of enzymes is usually followed by withdrawing a small portion of incubation mixture of enzyme and suicide substrate at various times and adding them, to assay mixture containing normal substrate. So theoretically, we look for a next indicator that can serve as a diagnostic tool for enzyme inactivation directly. We propose $\left(e_{i} / e=\xi\right)$ as the one that has been justified both numerically and analytically in this article.

$\frac{d\left(e_{i} / e\right)}{d t}=\frac{1}{E}\left(\frac{d e_{i}}{d t}\right)-\left(e_{i} / e\right)^{2} \frac{1}{e_{i}}\left(\frac{d e}{d t}\right)$

Using (1b) and (1e) in (5a),

$\frac{d \xi}{d t}=K^{\prime \prime} s-(\xi) \bar{K} s$

where $K^{\prime \prime}=\frac{k_{1} k_{3} k_{5}}{\left(k_{2}+k_{3}\right)\left(k_{4}+k_{5}\right)}$ and $\bar{K}=-\frac{k_{1} k_{3} k_{5}}{\left(k_{2}+k_{3}\right)\left(k_{4}+k_{5}\right)}$.

For condition of excess substrate, i.e., $s \approx s_{0}$, (5b) can be safely replaced with,

$\frac{d \xi}{d t}=K^{\prime \prime} s_{0}-(\xi) \bar{K} s_{0}$

Integrating with initial condition of $\xi(0)=0$,

$\xi=\frac{K^{\prime \prime}}{\bar{K}}\left(1-\exp ^{-\bar{K} s_{0} t}\right)$

Eq. (5d) suggests growth for the indicator $(\xi)$ as observed via numerical simulation. To have a consistency in the scale of the numerical results for the different region of analysis, i.e., from enzyme excess state via comparable concentration to substrate excess condition the indicator is revised accordingly via scaling technique that can even be interpreted with a probabilistic argument,

$e_{i} /\left[\min \left(s_{0}, e_{0}\right)-e_{i}\right]$ 
Table 1. Chosen system parameters (rate constants) and substrate-enzyme ratio along with the simulated data for the concentration of the species at steady state for a definite time $(t=100$ time units) are shown below case wise. $k_{2}, k_{3}, k_{4}, k_{5}$ being first order rate constants having unit of time ${ }^{-1}$. $k_{1}$ has unit of (conc.) $)^{-1}$ time $^{-1}$.

\begin{tabular}{lccrllccccc}
\hline Case & $\mathrm{s}_{0} / \mathrm{e}_{0}$ & \multicolumn{1}{c}{$k_{1}$} & \multicolumn{1}{c}{$k_{2}$} & $k_{3}$ & $k_{4}$ & $k_{5}$ & $c_{1}$ & $c_{2}$ & $e_{i}$ & $p$ \\
\hline 1 & 0.1 & 0.15 & 1000.0 & 2.0 & 0.1 & 400.0 & $1.4 \mathrm{E}(-3)$ & $6.0 \mathrm{E}(-6)$ & 0.25 & $6.0 \mathrm{E}(-5)$ \\
2 & 0.1 & 0.20 & 500.0 & 1.0 & 0.05 & 20.0 & $2.7 \mathrm{E}(-3)$ & $1.3 \mathrm{E}(-5)$ & 0.33 & $8.0 \mathrm{E}(-4)$ \\
3 & 0.1 & 0.10 & 500.0 & 0.5 & 2.0 & 0.01 & $1.8 \mathrm{E}(-3)$ & $4.5 \mathrm{E}(-4)$ & $4.5 \mathrm{E}(-4)$ & 0.09 \\
4 & 0.1 & 5.0 & 50.0 & 0.001 & 0.01 & 10.0 & 0.496 & $4.8 \mathrm{E}(-5)$ & $4.5 \mathrm{E}(-2)$ & $4.5 \mathrm{E}(-5)$ \\
5 & 1.0 & 0.50 & 500.0 & 0.2 & 5.0 & 0.1 & $9.8 \mathrm{E}(-4)$ & $3.9 \mathrm{E}(-5)$ & $3.7 \mathrm{E}(-4)$ & 0.019 \\
6 & 1.0 & 10.0 & 1000.0 & 0.5 & 50.0 & 0.1 & $6.03 \mathrm{E}(-3)$ & $6.02 \mathrm{E}(-5)$ & $7.0 \mathrm{E}(-4)$ & 0.39 \\
7 & 1.0 & 20.0 & 1000.0 & 0.1 & 0.05 & 50.0 & $1.4 \mathrm{E}(-2)$ & $2.75 \mathrm{E}(-5)$ & 0.16 & $1.6 \mathrm{E}(-4)$ \\
8 & 1.0 & 0.10 & 0.1 & 0.0001 & 0.1 & 50.0 & 0.38 & $7.1 \mathrm{E}(-7)$ & $3.6 \mathrm{E}(-3)$ & $7.0 \mathrm{E}(-6)$ \\
9 & 10.0 & 0.01 & 10.0 & 0.1 & 1.0 & 0.01 & $9.9 \mathrm{E}(-3)$ & $9.8 \mathrm{E}(-4)$ & $9.0 \mathrm{E}(-4)$ & 0.095 \\
10 & 10.0 & 1.0 & 500.0 & 0.05 & 2.0 & 1.5 & $2.2 \mathrm{E}(-2)$ & $2.7 \mathrm{E}(-4)$ & 0.041 & 0.055 \\
11 & 10.0 & 0.10 & 0.5 & 0.001 & 0.01 & 2.0 & 0.610 & $3.05 \mathrm{E}(-4)$ & 0.065 & $3.1 \mathrm{E}(-4)$ \\
12 & 10.0 & 5.0 & 1.0 & 0.0001 & 0.1 & 10.0 & 0.972 & $9.6 \mathrm{E}(-6)$ & $3.05 \mathrm{E}(-4)$ & $9.5 \mathrm{E}(-5)$ \\
13 & 10.0 & 0.20 & 10.0 & 0.05 & 0.2 & 0.1 & 0.122 & $2.0 \mathrm{E}(-2)$ & 0.22 & 0.44 \\
14 & 10.0 & 10.0 & 1.0 & 0.0001 & 1.0 & 0.01 & 0.992 & $9.8 \mathrm{E}(-5)$ & $9.5 \mathrm{E}(-5)$ & $9.8 \mathrm{E}(-3)$ \\
15 & 10.0 & 0.10 & 500.0 & 1.0 & 1.0 & 0.01 & $2.0 \mathrm{E}(-3)$ & $1.93 \mathrm{E}(-3)$ & $1.9 \mathrm{E}(-3)$ & 0.192 \\
16 & 10.0 & 0.10 & 500.0 & 1.0 & 0.01 & 1.0 & $1.72 \mathrm{E}(-3)$ & $1.65 \mathrm{E}(-3)$ & 0.179 & $1.7 \mathrm{E}(-3)$ \\
\hline
\end{tabular}

as $e_{i}<\operatorname{Min}\left(s_{0}, e_{0}\right)$. Thus, equations (5e) serve as indicator $\mathrm{I}_{3}$ for enzyme excess and substrate excess cases respectively and equally valid for comparable or equal enzyme-substrate ratio. Under ideal situation, $\mathrm{I}_{3}$ can have unity as the maximum value for inactivation. Very low value confirms no inactivation as evident from Table 1 and Table 2 . It is needless to mention that it is a dimensionless indicator.

(ii) $I_{2}$ and $I_{3}$ discussed previously are theoretical indicators, which are of greater concern to the theoretical chemists. However, for experimental analysis, if the system is such that it is possible to monitor the complex concentrations then we put forward a new experimental indicator given by,

$\mathrm{I}_{4}=\xi \cdot \min \left(s_{0}, e_{0}\right) /\left(s_{0}-s-e_{i}-p\right)$

Analytical derivation of it is in line with the previous indicator except the fact that under SSA $\left(c_{1}+c_{2}\right)$ is constant. Hence,

$$
\begin{aligned}
& \xi . \min \left(s_{0}, e_{0}\right) /\left(s_{0}-s-e_{i}-p\right) \\
& =\frac{K^{\prime \prime}}{\bar{K}\left(s_{0}-s-e_{i}-p\right)} e_{0}\left(1-\exp ^{-\bar{K} s_{0} t}\right)=\mathrm{I}_{4}
\end{aligned}
$$

which suggests growth like (5d) but has a special feature imbedded in them that will be discussed under section 3 . The idea stems from the $\left(\xi=e_{i} / e\right)$ ratio whose value greater than unity will confirm more than $50 \%$ inactivation. Since we are concerned with the initial kinetics to estimate inactivation and accumulation of intermediate is often an issue, augmenting the denominator with a factor that includes the intermediate is done and critically non-dimensionalised. A very low fractional value assures no inactivation and low to high integer value confirms inactivation (Tables 1 and 2).

(iii) This is another practical, rather experimental indicator that can report inactivation even under very special situations
Table 2. Calculated values of the standard indicator $I_{1}$ for the test cases and simulated values of the proposed indicators $\mathrm{I}_{2}, \mathrm{I}_{3}, \mathrm{I}_{4}, \mathrm{I}_{5}$ for understanding of suicidal inactivation of enzymes are provided below.

\begin{tabular}{lccccl}
\hline Case & $\mathrm{I}_{1}$ & $\mathrm{I}_{2}$ & $\mathrm{I}_{3}$ & $\mathrm{I}_{4}$ & $\mathrm{I}_{5}$ \\
\hline 1 & 10.0025 & 1096 & 0.33 & 23.0 & 0.92 \\
2 & 10.025 & 828 & 0.49 & 12.0 & 0.98 \\
3 & 2010.0 & 661950 & $4.5 \mathrm{E}(-4)$ & 0.07 & 0.17 \\
4 & 10.01 & 3301 & 0.047 & 0.012 & 0.09 \\
5 & 51.0 & 63775.5 & $3.7 \mathrm{E}(-4)$ & 0.38 & 0.27 \\
6 & 501.0 & 25062.5 & $7.0 \mathrm{E}(-4)$ & 0.13 & 0.11 \\
7 & 1.001 & 125.1 & 0.196 & 14.0 & 0.92 \\
8 & 1.002 & 2507 & $3.6 \mathrm{E}(-3)$ & 0.015 & 0.01 \\
9 & 10.10 & 23002.2 & $9.0 \mathrm{E}(-4)$ & 0.09 & 0.082 \\
10 & 0.233 & 526.2 & 0.11 & 24 & 0.7 \\
11 & 0.1005 & 113.5 & 0.07 & 0.31 & 0.09 \\
12 & 0.101 & 45.5 & $3.0 \mathrm{E}(-4)$ & 0.472 & 0.01 \\
13 & 0.30 & 68 & 0.28 & 2.5 & 0.62 \\
14 & 10.1 & 2278 & $9.0 \mathrm{E}(-5)$ & 0.63 & 0.09 \\
15 & 10.10 & 11410 & $1.9 \mathrm{E}(-3)$ & 0.51 & 0.33 \\
16 & 0.101 & 114 & 0.22 & 65.0 & 0.98 \\
\hline
\end{tabular}

when both the turnover and the suicidal path are less active and rapid accumulation of the complexes within the system takes place. Both the potential competing routes are rendered inactive, which can be identified from low $\mathrm{I}_{5}$ value. High value saturating to unity is an indication for inactivation. Borderline cases can be isolated too. The mathematical expression for the indicator is,

$\mathrm{I}_{5}=e_{i} /\left(e_{0}-e\right)$ 
The line of reasoning is like the fact that the suicidal path has a reduction in the number of moles due to the association of the enzyme and substrate molecules to form the inactivated enzyme. With initial number of moles $\left(n_{i}\right)$ and final mole number $\left(\mathrm{n}_{\mathrm{f}}\right)$, the reduction in mole number is calculated as,

$\left(\mathrm{n}_{\mathrm{i}}\right)-\left(\mathrm{n}_{\mathrm{f}}\right)=s_{0}+e_{0}-\left(s+p+e_{i}+c_{1}+c_{2}+e\right)$

And using (1h), (5i) is reduced to,

$\left(\mathrm{n}_{\mathrm{i}}\right)-\left(\mathrm{n}_{\mathrm{f}}\right)=\left(e_{0}-e\right)$

The ratio (5h) thus gives the probability of inactivation via association. This at the very outset includes cases of intermediate concentration accumulation as well (Table 1 and Table 2).

\subsection{Experimental relevance}

For an experimentalist with a suicide-substrate system at hand, measuring inactivated enzyme, $e_{i}$ is the most common route followed to identify inactivation. Systems may vary where monitoring either substrate $s$ or the product $p$ or both are possible. There are a very few systems where monitoring of the intermediate concentration may pose a problem. In such cases $\mathrm{I}_{3}, \mathrm{I}_{4}$ and $\mathrm{I}_{5}$ can be estimated using ( $1 \mathrm{~g}$ ) or ( $1 \mathrm{~h}$ ) provided $e_{i}$ and $e$ or $s$ and $p$ are known beforehand. However, measuring fractional life of enzyme $\mathrm{I}_{2}$ is a common kinetic exercise varying either the suicidal inhibitor or the enzyme as needed. As a final point, constancy in the value of the intermediate concentration or a linear fall-off in substrate concentration profile, if possible to measure, is an indication that steady state approximation is valid for the system and the equations derived are applicable.

\section{Results and Discussion}

A comprehensive table (Table 1) showing the reaction parameters for several test cases is analyzed for the understanding of the suicidal action of the enzyme over its turnover or catalytic path. Substrate excess, enzyme excess and cases with same enzyme-substrate concentration are dealt with thoroughly. The previous articles concerning suicide-substrate kinetics emphasized on some formative factor $(1+r) \mu$, where enzyme-substrate ratio and partition ratio guide suicidal enzyme inactivation under the condition of QSSA. Going by the data set of one of the prominent articles, ${ }^{1}$ it was apparent that though QSSA was recommended its validity over the time scale was not checked. For a system to abide by QSSA over a given time scale, the rate constants are crucial. It is needless to mention that whenever we say 'inactivation' we stick to suicidal enzyme inactivation unless otherwise mentioned.

Going by the Table 1, validity of QSSA is thoroughly checked over a time range $(0+t \rightarrow t=150$ time units), and the concentration of the concerned species are reported at $t=100$ time units. Reporting species concentration at $=100$ time units is only indicative, as steadiness in complex concentration is achieved via QSSA after the initial transient kinetics. Special attention is paid to $\left(c_{1}\right)$ with high concentration where most of the reactants are stored as intermediate without proceeding either to the turnover path or the suicidal route, but the system is still in a SS. This situation warrants special attention, which has never been addressed before (Case 4, Case 8, Case 11, Case 12 and Case 14). Concentrations of $p$ and $e_{i}$ reported at $t=100$ for such test cases will clarify the point raised. In addition we have also addressed the case that justifies the work done in previous articles $1,3,4$ to test the goodness of our endeavor.

Now focusing on Table 2, the values of the standard indicator $\mathrm{I}_{1}$ of previous articles and the indicators $\left(\mathrm{I}_{2}, \mathrm{I}_{3}, \mathrm{I}_{4}, \mathrm{I}_{5}\right)$ proposed in this article are explored to ascertain impromptu whether a system suffers suicidal inactivation of enzyme. Cases 1-4 with standard indicator value greater than 1 suggests no enzyme inactivation as discussed in articles; ${ }^{1,3-5}$ our proposed indicators however suggest a different opinion. For high value of $\mathrm{I}_{2}$ no inactivation is foreseen. Low $\mathrm{I}_{2}$ however is not a sufficient criteria to comment on inactivation due to some special feature of high intermediate concentration as stated in the previous paragraph (Case 7 and Case $11)$.

However, Indicator $\mathrm{I}_{3}$ is sometimes misleading especially for the enzyme excess cases as to what should be the cutoff value for asserting inactivation, though for all such indicators analytical articulation confirms growth. Hence, it is modified for three different ranges of enzyme-substrate ratio as discussed in section 2.5 via (5e). A similar line of analysis and argument is valid for other indicator $\mathrm{I}_{4}$ as well. Low fractional value for $\mathrm{I}_{4}$ confirms no inactivation and integer value even high confirms inactivation. For indicator $I_{5}$ the validity range is from 0.5 to unity. Value saturating to unity forecasts high inactivation. The same is corroborated in Figures 1, 2 and 3 for different test cases.

Some major pitfalls with $\mathrm{I}_{2}$ as indicator for a few special test cases may however suggest the fidelity of some indicators over the other. For enzyme excess cases, a special attention need to be conferred as the $I_{2}$ values are itself high for even inactivation cases to comment otherwise. This may be judged case wise (Case 1 and Case 2). After a closer look at the three tables (Tables 1,2 and 3) together, one may conclude that a high $\mathrm{I}_{2}$ is a sufficient condition to confer no enzyme inactivation, and no other indicator confirmation is needed in such cases. However low $\mathrm{I}_{2}$ foster inconclusive results regarding inactivation. Hence, one is motivated to look 

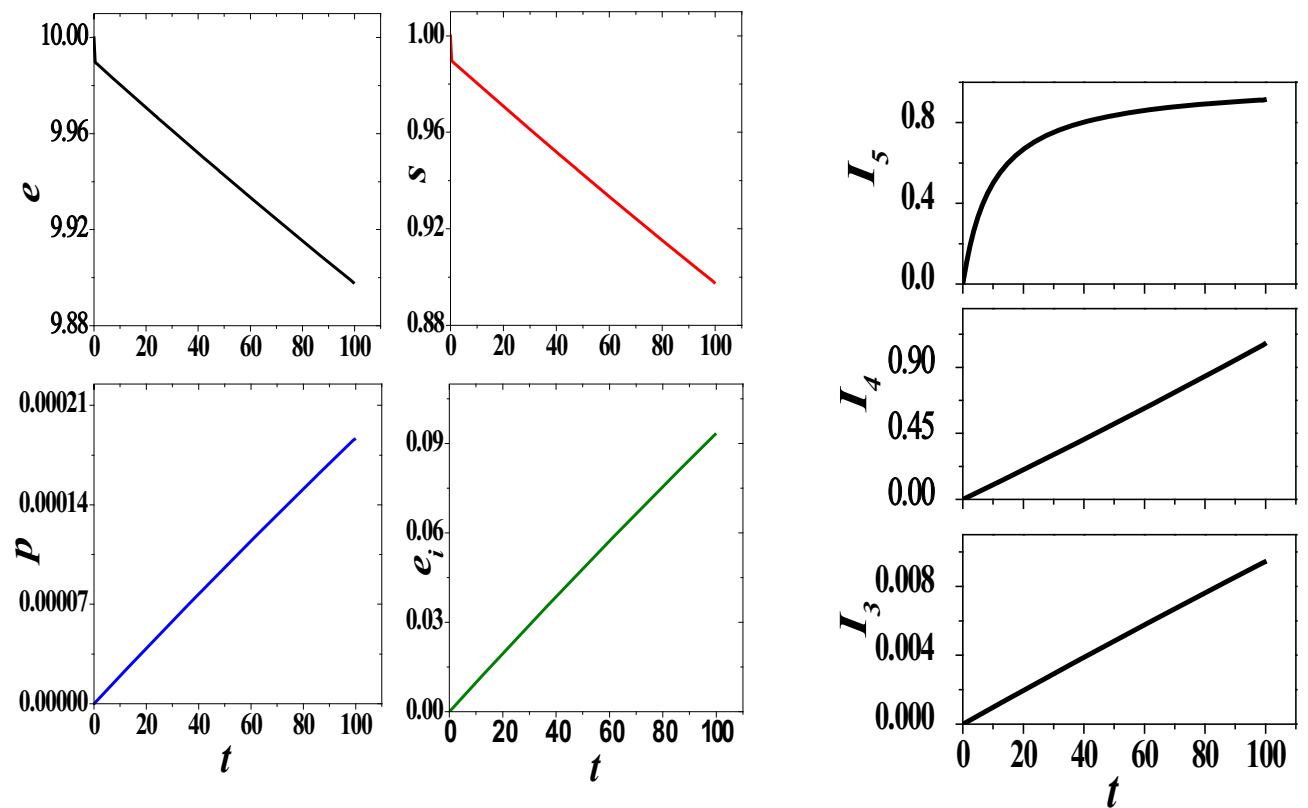

Figure 1. (a) Temporal profiles for enzyme $(e)$, substrate $(s)$, product $(p)$ and inactivated enzyme $\left(e_{i}\right)$ for case 1 in the panel of four. (b) Time variation of the proposed indicators showing enzyme inactivation in a panel of three.
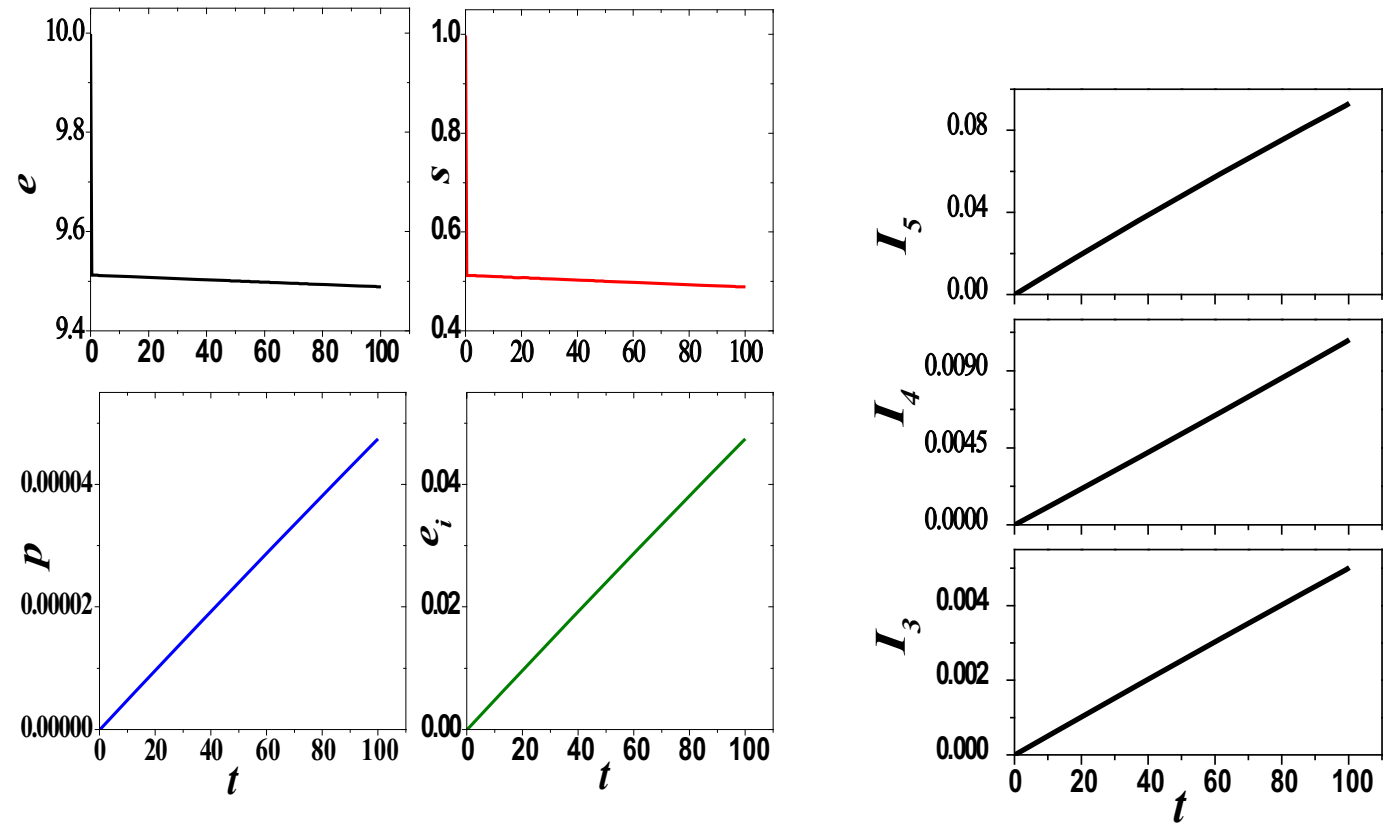

Figure 2. (a) Temporal profiles for enzyme $(e)$, substrate $(s)$, product $(p)$ and inactivated enzyme $\left(e_{i}\right)$ for case 4 in the panel of four. (b) Time variation of the proposed indicators showing almost no enzyme inactivation in the panel of three.

for some other measures $\mathrm{I}_{3}$ for a definite result (Case 4, Case 8).

For $\mathrm{I}_{3}$ as an indicator, a scaling technique has been adopted to stabilize the numerical values due to difference in scale for various substrate-enzyme ratio, starting from low to high substrate concentration as discussed in section 2.1. Very low $\mathrm{I}_{3}$ however confirms no inactivation. Though there may be some borderline cases with moderately high $\mathrm{I}_{2}$ and moderately low $\mathrm{I}_{3}$ with no unequivocal results (Cases 4, 10 and 15), such cases 

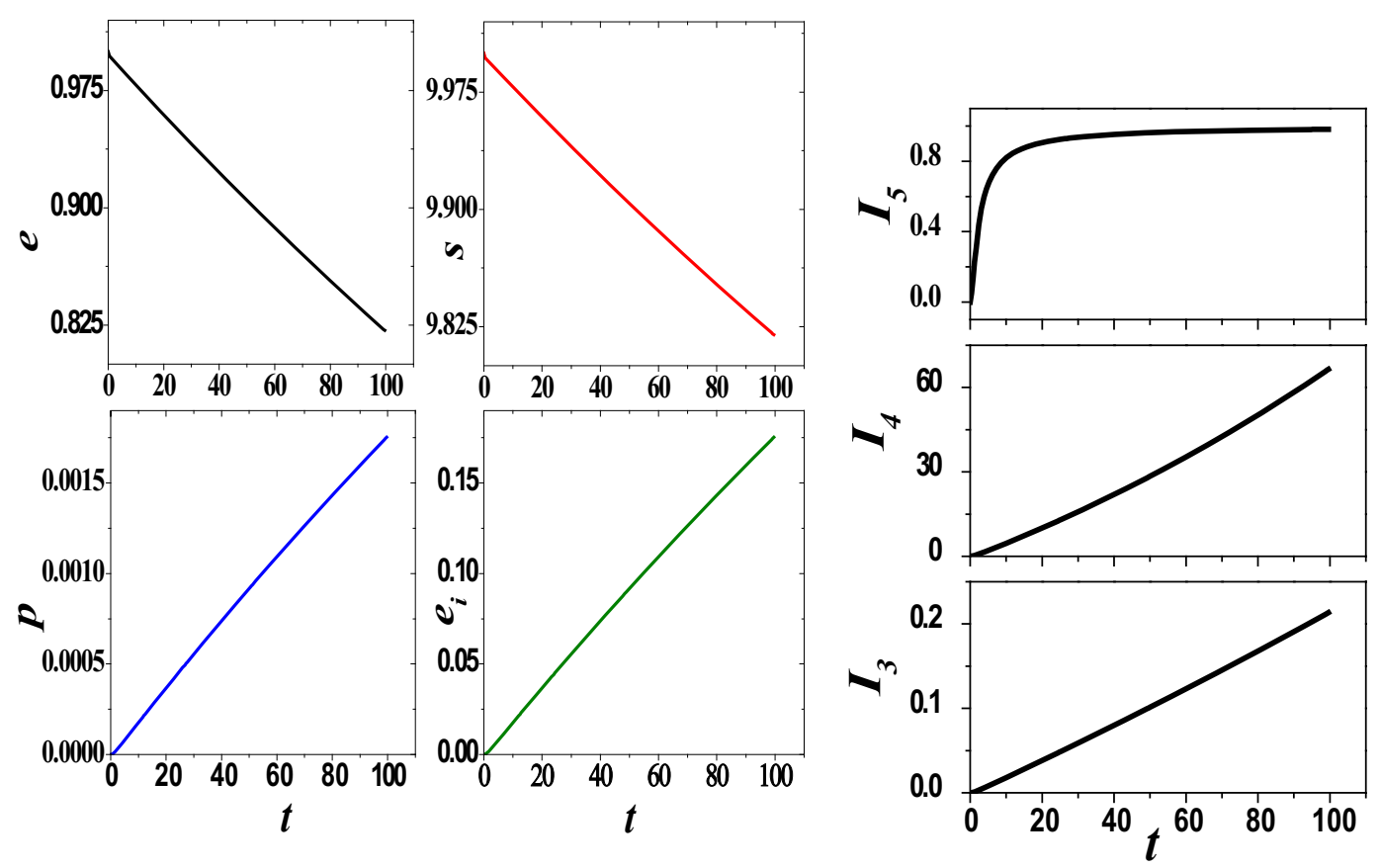

Figure 3. (a) Temporal profiles for enzyme (e), substrate $(s)$, product $(p)$ and inactivated enzyme $\left(e_{i}\right)$ for case 16 in the panel of four. (b) Time variation of the proposed indicators showing enzyme inactivation in the panel of three.

may finally be confirmed from some practical indicators like $\mathrm{I}_{4}$ and $\mathrm{I}_{5}$ where it is possible to estimate the intermediates in many such cases where accumulation of complexes is an issue (Cases 4, 8, 11, 12 and 14).

For the test cases 11 and 12, though a low fractional life suggests inactivation, but low values for $\mathrm{I}_{4}$ and $\mathrm{I}_{5}$ speak otherwise. This is a case of SSA where high intermediate concentration suggests no enzyme inactivation, that may either be followed experimentally by measuring $p$ and $e_{i}$ or through the indicators, which take into account the high intermediate and would forecast the real. The same may be argued for Cases 4, 8 and 14 as well. A final, all-inclusive Table 3 gives the complete picture of the investigations undertaken.

Finally, we highlight our major findings that include the following: (i) An apparently decaying enzyme profile may often be misleading and can delude one to infer suicidal inactivation. In such situations, proposed indicators, especially $\mathrm{I}_{3}, \mathrm{I}_{4}$ and $\mathrm{I}_{5}$ may work wonder. (ii) Rampant use of standard indicator $\left(\mathrm{I}_{1}\right)$ used in previous articles may often be elusive as breakdown of such criteria for inactivation is clear from test cases $1,2,7,8$, 11 and 12. (iii) The formative factor determining inactivation in previous articles have only a limited scope of application under substrate excess case and that too may often collapse under certain parametric conditions. (iv) Newly proposed indicators have a wider scope of application even in the enzyme excess and comparable
Table 3. Comments on enzyme inactivation based on the values of different indicators from Table 2 for different test cases and actual numerical observation on suicidal inactivation of enzymes. ' $\mathrm{Y}$ ' for yes and ' $\mathrm{N}$ ' for no for enzyme inactivation.

\begin{tabular}{llllll}
\hline Case & $\mathrm{I}_{1}$ & $\mathrm{I}_{2}$ & $\mathrm{I}_{3}$ & $\mathrm{I}_{4}$ & $\mathrm{I}_{5}$ \\
\hline 1 & $\mathrm{~N}$ & $\mathrm{Y}$ & $\mathrm{Y}$ & $\mathrm{Y}$ & $\mathrm{Y}$ \\
2 & $\mathrm{~N}$ & $\mathrm{Y}$ & $\mathrm{Y}$ & $\mathrm{Y}$ & $\mathrm{Y}$ \\
3 & $\mathrm{~N}$ & $\mathrm{~N}$ & $\mathrm{~N}$ & $\mathrm{~N}$ & $\mathrm{~N}$ \\
4 & $\mathrm{~N}$ & $\mathrm{~N}$ & $\mathrm{~N}$ & $\mathrm{~N}$ & $\mathrm{~N}$ \\
5 & $\mathrm{~N}$ & $\mathrm{~N}$ & $\mathrm{~N}$ & $\mathrm{~N}$ & $\mathrm{~N}$ \\
6 & $\mathrm{~N}$ & $\mathrm{~N}$ & $\mathrm{~N}$ & $\mathrm{~N}$ & $\mathrm{~N}$ \\
7 & $\mathrm{Y}$ & $\mathrm{Y}$ & $\mathrm{Y}$ & $\mathrm{Y}$ & $\mathrm{Y}$ \\
8 & $\mathrm{Y}$ & $\mathrm{N}$ & $\mathrm{N}$ & $\mathrm{N}$ & $\mathrm{N}$ \\
9 & $\mathrm{~N}$ & $\mathrm{~N}$ & $\mathrm{~N}$ & $\mathrm{~N}$ & $\mathrm{~N}$ \\
10 & $\mathrm{Y}$ & $\mathrm{N}$ & $\mathrm{Y}$ & $\mathrm{Y}$ & $\mathrm{Y}$ \\
11 & $\mathrm{Y}$ & $\mathrm{Y}$ & $\mathrm{N}$ & $\mathrm{N}$ & $\mathrm{N}$ \\
12 & $\mathrm{Y}$ & $\mathrm{Y}$ & $\mathrm{N}$ & $\mathrm{N}$ & $\mathrm{N}$ \\
13 & $\mathrm{Y}$ & $\mathrm{Y}$ & $\mathrm{Y}$ & $\mathrm{Y}$ & $\mathrm{Y}$ \\
14 & $\mathrm{Y}$ & $\mathrm{N}$ & $\mathrm{N}$ & $\mathrm{N}$ & $\mathrm{N}$ \\
15 & $\mathrm{~N}$ & $\mathrm{~N}$ & $\mathrm{~N}$ & $\mathrm{~N}$ & $\mathrm{~N}$ \\
16 & $\mathrm{Y}$ & $\mathrm{Y}$ & $\mathrm{Y}$ & $\mathrm{Y}$ & $\mathrm{Y}$ \\
\hline
\end{tabular}

enzyme-substrate situation cases. (v) Finally, Table 3 with $I_{3}, I_{4}$ and $I_{5}$ are the real and finer indicators that may be useful for the experimentalists studying enzymology or pharmacology. 


\section{Conclusions}

In the scientific literature, there are very few articles (see Introduction) involving the theoretical understanding of enzymatic reactions concerning stable suicidesubstrate. The possible reason could be that the theoretical workers were inhibited due to lack of data for real systems. Simultaneously, experimentalists with real examples were holed up because of lack of theoretical help to design experiments and kinetic analysis of experimental data. In this contribution, we try to break the vicious circle to furnish some analytical solutions along with some indicators to identify suicidal inactivation for those who want to apply to real enzymatic systems. With our proposed indicators, a high $\mathrm{I}_{2}$, a very low $\mathrm{I}_{3}$, a low fractional $\mathrm{I}_{4}$ and finally a relatively lower range of $\mathrm{I}_{5}$ (since value ranges from $0 \rightarrow 1$ ) confirm no inactivation. Conclusion may not be vice versa if conditions are reversed as each indicator needs to be analyzed individually. We hope that the treatment used here may be used to extrapolate to suit specific and real systems.

\section{Supplementary Information (SI)}

Figures S1-S3 are provided in Supplementary Information available at www.ias.ac.in/chemsci.

\section{Acknowledgements}

The author gratefully acknowledges valuable discussions and constructive comments of Prof. Kamal Bhattacharyya. Thanks are also due to CSIR, India, for a research associateship.

\section{References}

1. Burke M A, Maini P K and Murray J D 1990 On the kinetics of suicide substrate Biophys. Chem. 3781
2. Goeke A, Schilli C, Walcher S and Zerz E 2012 A note on the kinetics of suicide substrate J. Math. Chem. $\mathbf{5 0}$ 1373

3. Tatsunami S, Yago N and Hosoe M 1981 Kinetics of suicide substrates: Steady stste treatments and computeraided exact solutions Biochim. Biophys. Acta $\mathbf{6 6 2} 226$

4. Waley S G 1980 Kinetics of suicide substrates Biochem. J. 185771

5. Waley S G 1985 Kinetics of suicide substrates. Practical procedures for determining parameters Biochem. J. 227 843

6. Tudela J, Cánovas F G, Varón R, Carmona F G, Gálvez J and Lozano J A 1987 Transient-phase kinetics of enzyme inactivation induced by suicide substrates Biochim. Biophys. Acta 912408

7. Wang Z X 1990 Kinetics of suicide substrates J. Theor. Biol. 147497

8. Walsh C T 1984 Suicide substrates, mechanism-based enzyme inactivators: recent developments Annu. Rev. Biochem. 53493

9. Varon R, Garcia M, Garcis-Canovas and Tudela J 1990 Transient phase kinetics of enzyme inactivation induced by sucide substrates: enzymes involving two substrates J. Mol. Catal. 5997

10. Michaelis L and Menten M L 1913 Die Kinetik der Invertinwirkung Biochem. Z. 49333

11. Murray J D 2002 Mathematical Biology. I. An Introduction 3rd edn. (New York: Springer)

12. Munoz J L M, Molina F G, Ruiz P A G, Alarcon M M, Tudela J, Canovas F G and Lopez J N R 2008 Phenolic substrates and suicide inactivation of tyrosinase: kinetics and mechanism Biochem. J. 416431

13. Seki H, Xue S, Pellett S, Silhar P, Johnson E A and Janda K D 2016 Cellular protection of SNAP-25 against botulinum neurotoxin /A: inhibition of theoredoxin reductase through a suicide substrate mechanism J. Am. Chem. Soc. 1385568

14. Meijer M V, Smilde A, Tans G, Nesheim ME, Pannekoek H and Horrevoets A J G 1997 The suicide substrate reaction between plasminogen activator inhibitor 1 and thrombin is regulated by the cofactors vitronectin and heparin Blood 901874 